\title{
Overcoming a "Probable" Diagnosis in Antimitochondrial Antibody Negative Primary Biliary Cirrhosis: Study of 100 Sera and Review of the Literature
}

\author{
Nicola Bizzaro • Giovanni Covini - Floriano Rosina • Paolo Muratori • Elio Tonutti • \\ Danilo Villalta • Fiorenza Pesente • Maria Grazia Alessio • Marilina Tampoia • \\ Antonio Antico - Stefan Platzgummer • Brunetta Porcelli • Lucia Terzuoli • \\ Marco Liguori • Danila Bassetti • Ignazio Brusca • Piero L. Almasio • \\ Giuseppe Tarantino • Chiara Bonaguri • Paolo Agostinis • Elena Bredi • \\ Renato Tozzoli • Pietro Invernizzi • Carlo Selmi
}

Published online: 29 December 2010

(C) Springer Science+Business Media, LLC 2010

\begin{abstract}
Serum anti-mitochondrial antibodies (AMA) are the serological hallmark of primary biliary cirrhosis (PBC), yet up to $15 \%$ of $\mathrm{PBC}$ sera are AMA negative at routine indirect immunofluorescence (IIF) while being referred to as "probable" cases. The diagnostic role of $\mathrm{PBC}$-specific
\end{abstract}

Nicola Bizzaro, Elio Tonutti, Danilo Villalta, Maria Grazia Alessio, Marilina Tampoia, Antonio Antico, Stefan Platzgummer, Brunetta Porcelli, Lucia Terzuoli, Marco Liguori, Danila Bassetti, Ignazio Brusca, Chiara Bonaguri, and Renato Tozzoli: study group on autoimmune diseases of the Italian Society of Laboratory Medicine

N. Bizzaro $(\bowtie) \cdot F$. Pesente

Laboratorio di Patologia Clinica, Ospedale Civile,

Tolmezzo, Italy

e-mail: nicola.bizzaro@ass3.sanita.fvg.it

G. Covini $\cdot$ E. Bredi

Dipartimento di Gastroenterologia,

IRCCS Istituto Clinico Humanitas,

Rozzano, Italy

F. Rosina

Gastroenterologia ed Epatologia, Presidio Sanitario Gradenigo,

Torino, Italy

P. Muratori

Dipartimento di Medicina Interna, Cardioangiologia, Epatologia, Policlinico Universitario Sant'Orsola-Malpighi,

Bologna, Italy

E. Tonutti

Allergologia e Immunopatologia, Azienda Ospedale-Università, Udine, Italy

D. Villalta

Immunologia e Virologia, Azienda Ospedaliera,

Pordenone, Italy antinuclear antibodies (ANA) remains to be determined. We will report herein data on the accuracy of new laboratory tools for AMA and PBC-specific ANA in a large series of $\mathrm{PBC}$ sera that were AMA-negative at IIF. We will also provide a discussion of the history and current status of
M. G. Alessio

Laboratorio Analisi, Ospedali Riuniti,

Bergamo, Italy

\section{Tampoia}

Patologia Clinica, Policlinico Universitario,

Bari, Italy

\section{A. Antico}

Laboratorio Analisi, Ospedale Civile,

Cittadella, Italy

\section{S. Platzgummer}

Laboratorio Centrale, Ospedale Civile,

Merano, Italy

B. Porcelli $\cdot$ L. Terzuoli

Dipartimento di Medicina Interna,

Scienze Endocrino-Metaboliche e Biochimica,

Università degli Studi,

Siena, Italy

M. Liguori

Laboratorio Analisi, Azienda Ospedaliera G. Brotzu,

Cagliari, Italy 
AMA detection methods. We included IIF AMA-negative PBC sera $(n=100)$ and sera from patients with other chronic liver diseases $(n=104)$ that had been independently tested for IIF AMA and ANA; sera were blindly tested with an ELISA PBC screening test including two ANA (gp210, sp100) and a triple (pMIT3) AMA recombinant antigens. Among IIF AMA-negative sera, 43/100 (43\%) manifested reactivity using the $\mathrm{PBC}$ screening test. The same test was positive for $6 / 104$ (5.8\%) control sera. IIF AMA-negative/PBC screen-positive sera reacted against pMIT3 (11/43), gp210 (8/43), Sp100 (17/43), both pMIT3 and gp210 (1/43), or both pMIT3 and Sp100 (6/43). Concordance rates between the ANA pattern on HEp-2 cells and specific Sp100 and gp210 ELISA results in AMA-negative subjects were $92 \%$ for nuclear dots and Sp100 and 99\% for nuclear rim and gp210. Our data confirm the hypothesis that a substantial part of IIF AMA-negative (formerly coined "probable") PBC cases manifest disease-specific autoantibodies when tested using newly available tools and thus overcome the previously suggested diagnostic classification. As suggested by the recent literature, we are convinced that the proportion of AMA-negative PBC cases will be significantly minimized by the use of new laboratory methods and recombinant antigens.

\author{
D. Bassetti \\ Laboratorio di Patologia Clinica, Ospedale S. Chiara, \\ Trento, Italy \\ I. Brusca \\ Laboratorio Analisi, Ospedale Buccheri La Ferla, \\ Palermo, Italy
}

P. L. Almasio · G. Tarantino

Unità di Gastroenterologia ed Epatologia, Università degli Studi,

Palermo, Italy

C. Bonaguri

Laboratorio di Analisi Ematochimiche, Azienda Ospedaliera,

Parma, Italy

P. Agostinis

Divisione di Medicina Interna, Ospedale Civile,

Tolmezzo, Italy

\section{R. Tozzoli}

Laboratorio di Patologia Clinica, Ospedale Civile,

Latisana, Italy

P. Invernizzi $\cdot$ C. Selmi

Departimento di Medicina, IRCCS Istituto Clinico Humanitas,

Rozzano, Italy

C. Selmi

Dipartimento di Medicina Traslazionale,

Università degli Studi di Milano,

Milan, Italy
Keywords Autoimmune cholangitis $\cdot$ Nuclear dots $\cdot$ Rim like $\cdot$ Recombinant antigens $\cdot$ Diagnostic accuracy

\section{Serum AMA in Clinical Practice}

Primary biliary cirrhosis (PBC) is a chronic cholestatic liver disease in which biliary epithelial cells within the intrahepatic bile ducts are targeted by an immune-mediated injury, ultimately leading to liver fibrosis and cirrhosis [1]. PBC shares with other autoimmune diseases a striking female predominance [2], increased familial risk with a prevalence approaching $6 \%$ in relatives of index cases [3], and the incomplete concordance in monozygotic twins [4]. As internationally accepted, the diagnosis of PBC is based on the fulfillment of two out of three criteria: i.e., elevation of alkaline phosphatase, compatible histology, and serum anti-mitochondrial antibodies (AMA) [5]. Serum AMA is the major hallmark of PBC and is considered direct proof of the autoimmune pathogenesis of the disease. Despite manifesting among the highest disease sensitivity and specificity rates compared to other autoantibodies, there remains a subgroup of patients with undetectable AMA using routine methods [6]. Further, numerous studies suggested that AMA can appear before other histological or biochemical signs of liver injury [7] while AMA-positive subjects are expected to develop a clinical PBC profile in the subsequent years $[8,9]$. A classification proposed by a British group [10] included a "probable" diagnosis when two out of the three criteria (most often AMA positivity and compatible liver histology in the presence of normal liver enzymes) are present while a "definite" diagnosis is made only in the presence of all three. This classification may be seen as strict since the vast majority of asymptomatic AMA-positive individuals (particularly when serum reactivities are found using sensitive and specific methods) will eventually develop a classic picture of PBC during followup. Moreover, patients lacking detectable AMA, especially when indirect immunofluorescence (IIF) is used but otherwise presenting signs and symptoms of $\mathrm{PBC}$ should be regarded as affected by "AMA-negative PBC" (or autoimmune cholangitis) as they appear to follow a similar natural history when compared to their AMA-positive counterparts [6].

Based on these observations, it is obvious that developing a most sensitive and specific tool to determine serum AMA is of great importance in the diagnosis and management of patients with PBC. During routine tests, AMA are detected using IIF on frozen sections of mouse liver, stomach, and kidney in approximately $85 \%$ of PBC cases, thus not allowing an accurate diagnosis in a subgroup of patients. One major advancement in the serum diagnosis of PBC followed the cloning of the AMA autoantigens as three members of the 2oxo-acid dehydrogenase complex family [11] and the 
development of a triple-expression hybrid clone coined pMIT3 [12]. Besides AMA, multiple serum autoantibodies may be detected with lower frequencies in patients with $\mathrm{PBC}$ [13] along with a specific cytokine milieu [14]. In PBC sera, nondisease-specific ANA, particularly with a homogeneous, speckled and anti-centromere pattern at IIF [15] are detected in a subgroup of patients while the multiple nuclear dot and rim-like/membranous IIF patterns are highly specific for PBC. This is of particular importance for AMA-negative PBC cases as longitudinal data from different populations have confirmed the prognostic role of PBC-specific ANA [16, 17]. Interestingly, novel serum markers have been recently proposed for PBC [18, 19], yet their clinical significance and diagnostic impact remain elusive. To overcome these limitations and the scarcity of AMA-negative sera in a rare condition such as PBC, the Study Group on Autoimmune Diseases of the Italian Society of Laboratory Medicine collected PBC sera without detectable AMA at IIF to determine whether commercially available tests using recombinant mitochondrial and nuclear antigens could prove helpful in the diagnosis of IIF-AMA-negative cases. Our data confirm that new diagnostic tools significantly increase AMA and ANA sensitivity rates in this challenging subgroup of patients, as recently reported [20]. These results will be illustrated in this article along with a discussion of the current status of serum tests in PBC diagnosis and management.

\section{PBC Screening Tests in AMA-Negative PBC Sera}

\section{Patients and Methods}

Sera from PBC patients $(n=100)$ without detectable AMA at IIF were specifically obtained from 15 Italian referral centers between December 2006 and March 2008. In all cases, the diagnosis of $\mathrm{PBC}$ was based on the fulfillment of the other two internationally accepted criteria [5] and all patients had one liver biopsy performed during follow-up for diagnosis purposes. In 79 cases the liver biopsy was performed within 18 months of blood sampling and staging was arrayed in all cases: 17/79 (22\%) had stage I disease, 37 (47\%) stage II, 16 (20\%) stage III, and nine (11\%) stage IV according to Ludwig's criteria [21]. Among PBC cases, 90/ $100(90 \%)$ were females with a median age of 61 years (range 37-89); other clinical and biochemical features at the time of serum sampling are illustrated in Table 1 (left column). In particular, the Mayo score was calculated for all cases at the time of blood sampling as the only validated prognostic index in PBC [22].

Sera from patients $(n=104,60 / 104$ females, median age 45 , range 9-79) with other chronic liver diseases were used as controls and included type-1 autoimmune hepatitis (AIH$1, n=34)$, type-2 autoimmune hepatitis (AIH-2, $n=12)$, primary sclerosing cholangitis (PSC, $n=12$ ), hepatitis B virus-related cirrhosis $(n=9)$, and hepatitis $C$ virus-related cirrhosis $(n=25)$ or active hepatitis $(n=14)$.

The study protocol followed the ethical guidelines of the most recent Declaration of Helsinki (Edinburgh, 2000) and all subjects enrolled in the study provided written informed consent after being informed about the nature of the study.

Serum AMA and ANA were first assayed by IIF on sections of rat kidney, stomach and liver, and on HEp2 cells, respectively (INOVA, San Diego, CA, USA) in all serum samples. Slides were analyzed independently by two experienced pathologists (NB and FP) who were blinded to the sample clinical diagnosis and the reported autoantibody status. The results from the two observers were compared, and in cases of discrepancy the slide was jointly reevaluated until an agreement was reached.

A two-tier analysis was used for recombinant and purified antigens. First, sera were assayed with an ELISA screening test (PBC Screen, INOVA) based on the use of three recombinant (pMIT3) and purified coating antigens (gp210, Sp100) and the detection of IgG and IgA antibodies. Second, PBC screen-positive sera were tested with monospecific IgG ELISA assays (pMIT3, Sp100, and gp210). To avoid Ig isotype discrepancies, cases that tested positive at the PBC screen and negative at the IgG typing tests were also tested using an IgA conjugate (INOVA). Manufacturer cutoff values ( 25 units for all tests) were used to determine positive results. All tests were performed in duplicate at the Tolmezzo Laboratory of Clinical Pathology by a single operator who was blind to the sera clinical status; positive and negative control sera were included throughout the study. One assay lot was used for all samples to avoid lot-to-lot variability.

Comparison of the frequencies of laboratory and clinical features between groups was made using the Mann-Whitney $U$ test for continuous variables and the chi-square analysis for categorical variables. All analyses were two-tailed and $P$ values below 0.05 were considered statistically significant. Statistical analysis was performed using SPSS for Windows, version 11.5 (SPSS Inc, Chicago, IL, USA).

\section{Results}

We first confirmed that 100/100 IIF-AMA-negative sera tested negative at IIF on rodent tissues. Similarly, none of the 104 control sera tested positive for AMA at IIF. When ANA were analyzed on HEp-2 cells, 13/100 and 23/100 IIF-AMA-negative PBC sera were positive for rim-like and multiple nuclear dots patterns, respectively. As somehow expected, 9/100 IIF-AMA-negative PBC sera manifested a granular cytoplasmic AMA-like pattern on HEp-2 cells. Among control sera, 2/104 manifested a multiple nuclear dots ANA pattern. 
Table 1 Clinical and biochemical features of IIF-AMA-negative PBC cases enrolled in the study according to their IIF and recombinant antigen autoantibody status

\begin{tabular}{|c|c|c|c|c|}
\hline & IIF-AMA-negative $(n=100)$ & PBC screen positive $(n=44)$ & PBC screen negative $(n=56)$ & $P$ value \\
\hline Female sex $(n)$ & 90 & 40 & 50 & 0.7 \\
\hline Age (years) & $61(37-98)$ & $57(37-80)$ & $62(42-98)$ & 0.3 \\
\hline Disease duration (years) & $7(1-31)$ & $6(1-26)$ & $8(1-31)$ & 0.2 \\
\hline UDCA treatment $(n)$ & $60(60 \%)$ & $20(45 \%)$ & $40(71 \%)$ & 0.005 \\
\hline Encephalopathy $(n)$ & $2(2 \%)$ & $1(2.3 \%)$ & $1(1.8 \%)$ & 0.8 \\
\hline Ascites $(n)$ & $7(7 \%)$ & $4(9.1 \%)$ & $3(5.3 \%)$ & 0.5 \\
\hline Digestive bleeding $(n)$ & $2(2 \%)$ & $1(2.3 \%)$ & $1(1.8 \%)$ & 0.8 \\
\hline Alkaline phosphatase (UI/L) & $150(22-2,943)$ & $131(27-2,943)$ & $171(22-812)$ & 0.2 \\
\hline Alanine aminotransferase $(\mathrm{UI} / \mathrm{L})$ & $36(7-515)$ & $33(7-139)$ & $39(11-555)$ & 0.3 \\
\hline$\gamma$-glutamyl transferase $(\mathrm{U} / \mathrm{L})$ & $113(14-1,822)$ & $117(14-1,822)$ & $105(14-765)$ & 0.4 \\
\hline Total bilirubin (mg/dL) & $0.7(0.2-41.4)$ & $0.6(0.2-6.1)$ & $0.7(0.2-41.4)$ & 0.2 \\
\hline Albumin $(\mathrm{g} / \mathrm{L})$ & $4.0(2.6-6.2)$ & $4.0(2.6-6.2)$ & $4.0(2.6-5.1)$ & 0.9 \\
\hline Prothrombin time $(\%)$ & $98(62-100)$ & $99(70-100)$ & $98(62-100)$ & 0.4 \\
\hline Mayo score & $4.94(1.89-10.93)$ & $4.77(1.89-8.01)$ & $5.00(2.89-10.93)$ & 0.08 \\
\hline Stage I-II & $54 / 79(68 \%)$ & $23 / 79(29 \%)$ & $31 / 79(39 \%)$ & 0.8 \\
\hline
\end{tabular}

Continuous variables are expressed as median (range). $P$ values refer to the comparison between PBC screen positive and negative cases

Among IIF-AMA-negative PBC sera, 43/100 tested positive at the $\mathrm{PBC}$ Screen assay. When single antigens were used, 11/100 sera recognized pMIT3 alone (including 3 sera with only IgA reactivity), 8/100 gp210 only, and 17/100 Sp100. Seven of 100 sera reacted against two antigens as follows: one against pMIT3 and gp210 and six against pMIT3 and Sp100. The pMIT3 reactivity was overall observed in 18/100 (18\%) of IIF-AMA-negative PBC sera while anti-gp210 and anti-Sp100 antibodies were positive in $9 / 100$ and 23/100 PBC cases, respectively. Among control sera, six tested positive at the PBC Screen (four reacting against pMIT3 and 2 against Sp100); once the serum code was broken, these sera were found to be from patients with AIH-1 and a chart review confirmed the diagnosis in all cases 1 year after the serum was obtained. The PBC screen test had a sensitivity of $43 \%$ among IIF-AMA-negative PBC sera (subdivided into $18 \%$ for pMIT3, 9\% for gp210, and $23 \%$ for Sp100 when single antigens were used) while the test cumulative specificity was $94.2 \%$. Concordance between the ANA pattern on HEp-2 cells and specific Sp100 and gp210 ELISA results in AMA-negative subjects was $92 \%$ for nuclear dots and Sp100 and 99\% for nuclear rim and gp210 (Table 2). Of the nine sera that showed a cytoplasmic mitochondrial-like pattern on the HEp-2 cells but were IIF-AMA-negative on rodent tissues, all were positive for PBC-screen and MIT3.

When IIF-AMA-negative PBC cases were arrayed according to the PBC Screen reactivities (Table 1), we observed that serum positivity did not identify a clinically relevant subgroup of patients. One exception was the fact that patients who tested negative at $\mathrm{PBC}$ screen were more frequently taking ursodeoxycholic acid (UDCA) compared to their positive counterpart ( $71 \%$ vs. $45 \%, P=0.005$ ). Similarly and following previous reports on the clinical significance of PBC-specific ANA [17], we analyzed whether the ANA and anti-gp210 status was associated with a different clinical or biochemical phenotype (Table 3). We demonstrated that patients who were ANA positive at IIF had shorter disease duration ( 6 vs. 9 years) and were less likely to be receiving UDCA treatment (16\% vs. $43 \%)$ compared to their ANA negative counterparts. The shorter disease duration was also confirmed when anti-Sp100 was analyzed. Quite surprisingly, no difference could be observed in any of the included clinical features when patients were classified according to their serum anti-gp210 status.

Table 2 Concordance of IIF-ANA findings (subdivided into multiple nuclear dots, MND, and rim-like) with the purified antigens gp210, Sp100 in 100 IIF-AMA-negative patients with PBC

\begin{tabular}{lllllll}
\hline & & \multicolumn{2}{l}{ MND ANA } & & \multicolumn{2}{l}{ Rim-like ANA } \\
\cline { 5 - 6 } & & + & & & + & - \\
\hline Sp100 & + & 19 & 4 & & \\
& - & 4 & 73 & & 0 \\
gp210 & + & & & & 12 & 0 \\
Concordance & - & & & & 1 & 87 \\
\hline
\end{tabular}




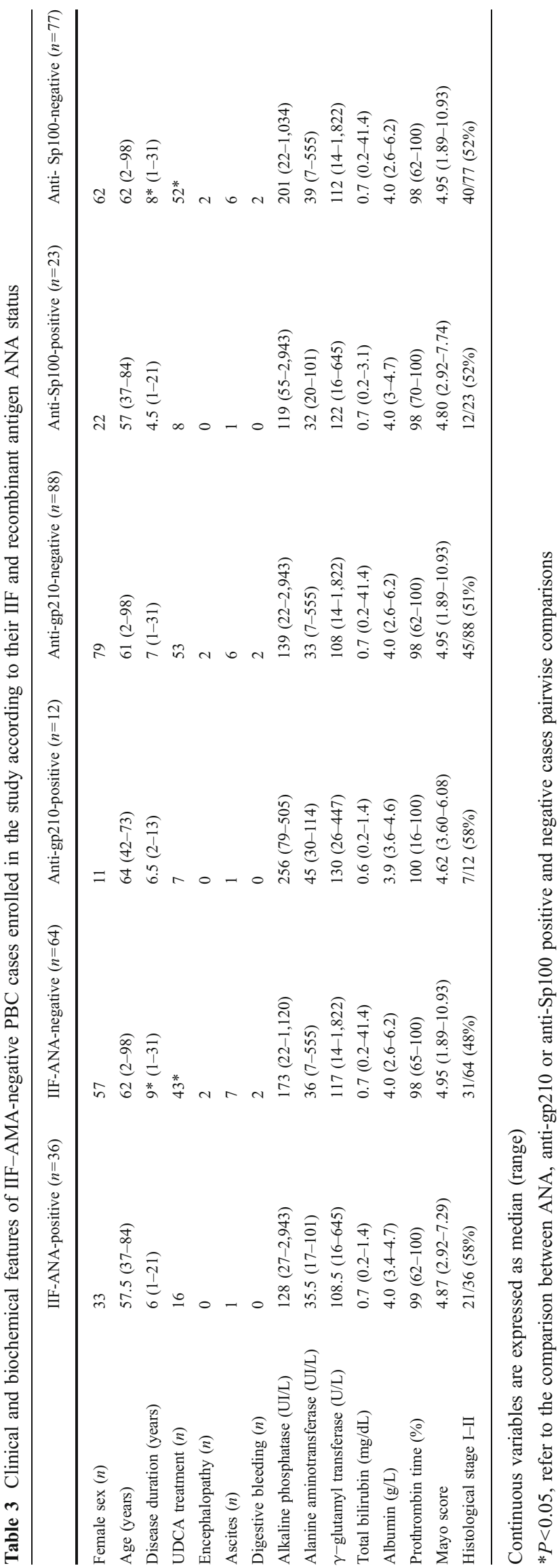

\section{The History of AMA in PBC}

Following earlier reports of AMA association with PBC [23], the pioneer work of Eric Gershwin [11] first demonstrated that AMA are directed against components of the 2-oxoacid dehydrogenase complex (2-OADC) family, including the E2 subunis of the pyruvate dehydrogenase complex (PDC-E2), the branched chain 2-oxo-acid dehydrogenase complex (BCOADC-E2), and the oxoglutarate dehydrogenase complex, as well as the dihydrolipoamide dehydrogenase-binding protein and the $\mathrm{E} 1 \alpha$ subunit of pyruvate dehydrogenase complex (PDC-E1 $\alpha$ ). The E2 subunits of the three enzymes manifest a significantly protein homology and, from an evolutionary standpoint, 2OADC proteins are highly conserved across species [24]. In all three major antigens, epitopes contain the peptide motif aspartic acid-lysine-arginine, with lipoic acid covalently bound to the lysine $(\mathrm{K})$ residue. The role of lipoic acid in the epitope recognition by AMA is unclear but accumulating evidence supports a necessary role for this residue in antibody recognition [25] while possibly being prone to xenobiotic modifications as lipoic acid is exposed on the outer surface [26-29] thus explaining the environmental influence on disease onset and the proposed geoepidemiology [30]. From a clinical standpoint, "autoimmune cholangitis" was first coined to indicate AMA-negative PBC cases with detectable serum ANA while a broader definition has been later suggested more recently to indicate the presence of serum ANA and/or smooth muscle positivity and/or hypergammaglobulinemia, serum AMA negativity by IIF, biochemical and/or histological features of cholestatic and hepatocellular injury, after chronic viral, metabolic, or toxic liver disease have been ruled out [31]. Consensus is still awaited on this issue and should be sought to avoid misunderstanding in the clinical and histological evaluation of patients with chronic biliary diseases.

\section{The Present of AMA in PBC}

We herein describe for the first time that a new commercially available autoantibody array including the three recombinant AMA and two major disease-specific ANA autoantigens allows detecting $\mathrm{PBC}$-specific autoantibodies in $43 \%$ of a large series of sera-proven AMA-negative at IIF. Of note, these data were gathered from 100 IIF-AMAnegative sera, estimated to represent approximately 1,000 patients with $\mathrm{PBC}$.

The diagnosis of $\mathrm{PBC}$ remains significantly dependent on the presence of serum AMA, given that these represent highly specific disease markers [32] and that liver histology is associated with a low predictive value [33]. Indeed, the diagnosis of PBC is made when two out of three 
internationally accepted criteria are fulfilled, i.e., presence of serum anti-AMA, increased enzymes indicating cholestasis (i.e., alkaline phosphatase) for longer than 6 months, and compatible or diagnostic liver histology. A classification made by a British group [10] proposed a "probable" diagnosis when two out of the three criteria (most often AMA positivity and compatible liver histology in the presence of normal liver enzymes) are present. Accordingly, a "definite" diagnosis should be made only in the presence of all three. This classification may be seen as strict since the vast majority of asymptomatic AMA-positive individuals (particularly when serum reactivities are found using sensitive and specific methods) will eventually develop a classic picture of PBC during follow-up. Moreover, patients lacking detectable AMA, especially when IIF is used but otherwise presenting signs and symptoms of $\mathrm{PBC}$ should be regarded as affected by "AMA-negative PBC" (or autoimmune cholangitis) as they appear to follow a similar natural history when compared to their AMA-positive counterparts [6].

Given their high specificity and their early appearance prior to disease manifestations [9], AMA is a crucial hallmark for the diagnosis of PBC as their positivity, along with elevated cholestasis markers, allows a definitive diagnosis [33]. While AMA can be regarded as the most specific autoantibodies in the field of autoimmunity it is quite frustrating that as many as $15 \%$ of patients with $\mathrm{PBC}$ [6] do not manifest antimitochondrial reactivity when tested by IIF, the routine method for autoantibody testing. For these reasons, chipping away at the minority of $\mathrm{PBC}$ cases in which serum AMA cannot be detected is of seminal importance for the clinical diagnosis and management of patients and for clinical epidemiology. Following the original cloning of the autoantigen [11], the introduction of recombinant AMA antigens [12, 34, 35] and the report that a significant subgroup of patients with $\mathrm{PBC}$ manifest disease-specific serum ANA $[17,36]$ has led to the possibility that the AMA-negative subgroup may indeed be rapidly overcome. The current IIF limitations have major implications in the determination of pathogenetic role for AMA as well as for the diagnostic workup and these implications will be discussed in light of the data presented herein.

First, data on the importance of sensitive AMA testing in PBC influence both the diagnosis and management sides of medical practice. Even in the absence of longitudinal data from large population-based studies, AMA is believed to appear in asymptomatic individuals decades prior to the onset of PBC [8]. Metcalf et al. [8] reported that $76 \%$ of asymptomatic individuals with serum AMA will eventually develop symptoms of PBC over an 11- to 24-year followup period. These observations have obvious implications for the possible early diagnosis of PBC in which establish- ing a medical treatment could lead to significant results [37-39]. Second, an autoimmune pathogenesis of PBC is widely accepted [40], yet several issues remain debated, as in the case of the lack of clinical benefit from immune suppressants or the absence of direct proof of AMA pathogencity. Antibodies against various mitochondrial enzymes can be frequently detected in patients with chronic or acute liver diseases of other etiologies. In the case of acute liver failure secondary to acetaminophen, however, PBC-specific AMA are detected in $41 \%$ of patients thus having possible implications for the mechanisms of $\mathrm{PBC}$ onset [41]. On the other hand, other nonPBC AMA responses are commonly directed at different epitopes than in patients with PBC and have led to significant inaccuracies regarding the specificity of the AMA response. Serum AMA include all three major immunoglobulin isotypes, i.e., IgG, IgM, and IgA with no major differences in epitope specificity or diagnostic significance. AMA has been detected also in bile, saliva, and urine from affected individuals [42-45]; their relevance to $\mathrm{PBC}$ pathogenesis remains unknown although the hypothesis of a direct IgA role in the bile duct injury is fascinating [46].

In both these issues, our data are of significant importance as we strongly support that AMA-negative patients with $\mathrm{PBC}$ are progressively reducing in proportion with obvious implications to the AMA pathogenic role. Following a multicenter effort, we gathered the largest reported population of patients with $\mathrm{PBC}$ who tested negative for AMA using the IIF method on rodent tissues. First, we evaluated whether the use of new ELISA tests for detection of antibodies to MIT3, gp210 and Sp100 could enable a diagnosis of definite PBC in AMA-IIF-negative subjects. The use of a screening test that includes the hybrid recombinant MIT3 and the Sp100 and g210 antigens proved to be superior to IIF because it has greater diagnostic sensitivity. In fact, all but two of the AMAIIF-positive patients and almost half of the AMA-IIFnegative patients tested positive to the PBC screen test. Regarding antibodies against the MIT3 antigen, the higher sensitivity of the ELISA test in AMA-positive subjects was confirmed in this study, as already found in other studies $[12,32]$. Most importantly, our data confirmed recent reports from a large multicenter study that also included a subgroup of the PBC sera investigated in the present work [20]. Although the data warrant prospective confirmation, a putative diagnostic algorithm could include an ELISA test based on pMIT3 might as a confirmation test for positive results obtained by the screening test. Specificity remains a major issue for screening tests, as well illustrated by celiac disease [47]. In the case of ELISA PBC screen test and MIT3 specificity rates were $94.2 \%$ and $96.2 \%$, respectively. Of note, six control sera (from patients with type $1 \mathrm{AIH}$ ) tested negative to AMA-IIF but positive to ELISA assays 
and were considered falsely positive because, at the time of testing and in 1 year follow-up, there were no clinical manifestations or biochemical signs of PBC. However, the possibility of a subsequent appearance of overlap syndrome features should not be overlooked [48]. We failed to determine significant differences between AMA-positive and AMA-negative patients in terms of epidemiological, clinical, or biochemical features, thus confirming what has already been observed [6], that is, that the presence of AMA has diagnostic significance but does not influence the clinical course of patients with PBC. Based on our current knowledge, thus is not surprising. Although highly specific for PBC, AMA do not predict the clinical phenotype nor the prognosis of patients, similar to what has been observed with the vast majority of autoantibodies in other autoimmune diseases, with the possible exception of anti-dsDNA and lupus-associated nephritis [49]. This lack of clinical correlation raises the long-standing issue of AMA pathogenetic role in $\mathrm{PBC}$ that is well represented by recent animal data on cholangitis improvement following B cell depletion [50] or the AMA persistence following liver transplantation [51]. Of interest, experimental data support the hypothesis that the unique apoptotic features of bile duct cells [52] concur with AMA to determine the disease tissue specificity in a macrophage-dependent fashion [53]. It was first demonstrated that PDC-E2 remains intact and retains its immunogenicity during cholangiocyte apoptosis, secondary to a cell-specific lack of glutathionylation of biliary epithelial cells [54]. The intact PDC-E2 in apoptotic blebs (i.e., apotopes) could be then uptaken by local antigen presenting cells and transferred to regional lymph nodes for priming of cognate $\mathrm{T}$ cells thus initiating $\mathrm{PBC}$ [52].

The issue of ANA reactivity in $\mathrm{PBC}$ warrants further discussion [55]. Only two previous studies investigated the diagnostic of serum AMA using an ELISA method [56, 57], both on smaller numbers of patients. One study [57] on 13 sera reported sensitivity and specificity rates of $38 \%$ and $94 \%$ for Sp100 and of $31 \%$ and $99 \%$ for gp 210 while the other included 22 patients [56] with sensitivity and specificity rates of $55 \%$ and $99.2 \%$ for Sp100 and $45 \%$ and $100 \%$ for gp 210 . Our larger series was characterized by lower sensitivity (23\% for Sp100, 9\% for gp 210 ) while specificity rates were comparable $(98 \%$ for Sp100 and $100 \%$ for gp210). Quite surprisingly, our cross-sectional data could not recapitulate the reported clinical differences based on PBC-specific ANA reactivity [58] although different antigen preparation could account for these discrepancies.

\section{The Future of AMA in PBC}

The advent of recombinant antigens [12] and new automated high-throughput methods paved the way to new tools for AMA detection in $\mathrm{PBC}$ cases but most studies are indeed performed in established series rather than in the general population to discriminate the assay specificity [59]. The Davis group proposed a novel bead-based assay that utilizes recombinant antigens to further reduce the prevalence of AMA-negative sera among otherwise established PBC cases [35]. The proposed method improves the sensitivity associated with spatial presentation, essential for conformational epitopes, while allowing the detection of multiple antigens at once in a small amount of serum [6062]. The assay has important advantages compared to previous methods due to the possibility to use a large and variable number of individual bead sets and of customization to include not only autoantibodies but possibly other serum markers of immunity or inflammation. Moreover, the proposed tool incorporates the advantages of a fully automated procedure to significantly reduce operator variability and maximizes standardization. Recombinant antigens, i.e., PDC-E2, BCOADC-E2, OADC-E2, were purified, applied to the activated beads, and assayed in a standardized manner with a large series of PBC sera [63]. The technological improvement was also reflected in the AMA detection in previously nonreactive sera. Six of these sera $(20 \%)$ reacted with at least one antigen and $10 \%$ with more than one using our bead-based assay, thus making the possibility of a structural bias unlikely. Moreover, AMA titers in these previously negative sera often reaching levels similar to other highly positive sera in some cases, thus further suggesting the importance of conformation in determining serum reactivities. One interesting observation that resulted from the analysis of data is that all of the sera that proved AMA-positive with the new assay were also ANA-positive at IIF; a feature shared only by $48 \%$ of the remaining AMA negatives whose prevalence appears similar to previous reports and the reasons for this discrepancy remain to be elucidated. Nevertheless, this method is characterized by high costs and is thus poorly applicable in clinical routine tests. For this reason, it is necessary to determine whether more readily available tools are capable to increase the diagnostic significance of AMA and ANA tests in everyday clinical practice and in the case of high a priori suspicion. We report herein the results of the clinical use of a commercially available PBC autoantibody test in a large cohort of IIF-AMA negative sera from patients with an established diagnosis of PBC. While we encourage the development of a prospective study, our data support the view that AMA-negative PBC sera represent the current laboratory limitations thus pointing toward the overcoming of a probable diagnosis of PBC. Finally, we foresee that new biological markers such as microRNA [64], genetic polymorphisms [65, 66], or epigenetics [67, 68] may prove of significant importance in the future of $\mathrm{PBC}$ diagnosis and management. 


\section{References}

1. Selmi C, Zuin M, Gershwin ME (2008) The unfinished business of primary biliary cirrhosis. J Hepatol 49:451-460

2. Gleicher N, Barad DH (2007) Gender as risk factor for autoimmune diseases. J Autoimmun 28:1-6

3. Gershwin ME, Selmi C, Worman HJ, Gold EB, Watnik M, Utts J, Lindor KD, Kaplan MM, Vierling JM (2005) Risk factors and comorbidities in primary biliary cirrhosis: a controlled interviewbased study of 1,032 patients. Hepatology 42:1194-1202

4. Selmi C, Mayo MJ, Bach N, Ishibashi H, Invernizzi P, Gish RG, Gordon SC, Wright HI, Zweiban B, Podda M, Gershwin ME (2004) Primary biliary cirrhosis in monozygotic and dizygotic twins: genetics, epigenetics, and environment. Gastroenterology 127:485-492

5. Kaplan MM, Gershwin ME (2005) Primary biliary cirrhosis. N Engl J Med 353:1261-1273

6. Invernizzi P, Crosignani A, Battezzati PM, Covini G, De Valle G, Larghi A, Zuin M, Podda M (1997) Comparison of the clinical features and clinical course of antimitochondrial antibody-positive and -negative primary biliary cirrhosis. Hepatology 25:1090-1095

7. Kisand KE, Metskula K, Kisand KV, Kivik T, Gershwin ME, Uibo R (2001) The follow-up of asymptomatic persons with antibodies to pyruvate dehydrogenase in adult population samples. J Gastroenterol 36:248-254

8. Metcalf JV, Mitchison HC, Palmer JM, Jones DE, Bassendine MF, James OF (1996) Natural history of early primary biliary cirrhosis. Lancet 348:1399-1402

9. Prince MI, Chetwynd A, Craig WL, Metcalf JV, James OF (2004) Asymptomatic primary biliary cirrhosis: clinical features, prognosis, and symptom progression in a large population based cohort. Gut 53:865-870

10. Metcalf JV, Bhopal RS, Gray J, Howel D, James OF (1997) Incidence and prevalence of primary biliary cirrhosis in the city of Newcastle upon Tyne, England. Int J Epidemiol 26:830-836

11. Gershwin ME, Mackay IR, Sturgess A, Coppel RL (1987) Identification and specificity of a cDNA encoding the $70 \mathrm{kd}$ mitochondrial antigen recognized in primary biliary cirrhosis. J Immunol 138:3525-3531

12. Moteki S, Leung PS, Coppel RL, Dickson ER, Kaplan MM, Munoz S, Gershwin ME (1996) Use of a designer triple expression hybrid clone for three different lipoyl domain for the detection of antimitochondrial autoantibodies. Hepatology 24:97103

13. Agmon-Levin N, Shapira Y, Selmi C, Barzilai O, Ram M, SzyperKravitz M, Sella S, Katz BS, Youinou P, Renaudineau Y, Larida B, Invernizzi P, Gershwin ME, Shoenfeld Y (2010) A comprehensive evaluation of serum autoantibodies in primary biliary cirrhosis. J Autoimmun 34:55-58

14. Barak V, Selmi C, Schlesinger M, Blank M, Agmon-Levin N, Kalickman I, Gershwin ME, Shoenfeld Y (2009) Serum inflammatory cytokines, complement components, and soluble interleukin 2 receptor in primary biliary cirrhosis. J Autoimmun 33:178182

15. Bogdanos DP, Baum H, Vergani D (2003) Antimitochondrial and other autoantibodies. Clin Liver Dis 7:759-777, vi

16. Nakamura M, Shimizu-Yoshida Y, Takii Y, Komori A, Yokoyama T, Ueki T, Daikoku M, Yano K, Matsumoto T, Migita K, Yatsuhashi H, Ito M, Masaki N, Adachi H, Watanabe Y, Nakamura Y, Saoshiro T, Sodeyama T, Koga M, Shimoda S, Ishibashi H (2005) Antibody titer to gp210-C terminal peptide as a clinical parameter for monitoring primary biliary cirrhosis. J Hepatol 42:386-392

17. Wesierska-Gadek J, Penner E, Battezzati PM, Selmi C, Zuin M, Hitchman E, Worman HJ, Gershwin ME, Podda M, Invernizzi P
(2006) Correlation of initial autoantibody profile and clinical outcome in primary biliary cirrhosis. Hepatology 43:1135-1144

18. Santiago M, Baron M, Miyachi K, Fritzler MJ, Abu-Hakima M, Leclercq S, Bell M, Hudson M, Mathieu JP, Taillefer S, Jones N, Docherty P, Khraishi M, Markland J, Pope J, Robinson D, Smith D, Sutton E (2008) A comparison of the frequency of antibodies to cyclic citrullinated peptides using a third generation anti-CCP assay $(\mathrm{CCP} 3)$ in systemic sclerosis, primary biliary cirrhosis and rheumatoid arthritis. Clin Rheumatol 27:77-83

19. Preub B, Berg C, Altenberend F, Gregor M, Stevanovic S, Klein R (2007) Demonstration of autoantibodies to recombinant human sulphite oxidase in patients with chronic liver disorders and analysis of their clinical relevance. Clin Exp Immunol 150 (2):312-321

20. Liu H, Norman GL, Shums Z, Worman HJ, Krawitt EL, Bizzaro N, Vergani D, Bogdanos DP, Dalekos GN, Milkiewicz P, Czaja AJ, Heathcote EJ, Hirschfield GM, Tan EM, Miyachi K, Bignotto M, Battezzati PM, Lleo A, Leung PS, Podda M, Gershwin ME, Invernizzi P (2010) PBC screen: an IgG/IgA dual isotype ELISA detecting multiple mitochondrial and nuclear autoantibodies specific for primary biliary cirrhosis. J Autoimmun 35:436-442

21. Ludwig J, Dickson ER, McDonald GS (1978) Staging of chronic nonsuppurative destructive cholangitis (syndrome of primary biliary cirrhosis). Virchows Arch A Pathol Anat Histol 379:103112

22. Dickson ER, Grambsch PM, Fleming TR, Fisher LD, Langworthy A (1989) Prognosis in primary biliary cirrhosis: model for decision making. Hepatology 10:1-7

23. Walker JG, Doniach D, Roitt IM, Sherlock S (1965) Serological tests in diagnosis of primary biliary cirrhosis. Lancet 39:827-831

24. Padgett KA, Selmi C, Kenny TP, Leung PS, Balkwill DL, Ansari AA, Coppel RL, Gershwin ME (2005) Phylogenetic and immunological definition of four lipoylated proteins from Novosphingobium aromaticivorans, implications for primary biliary cirrhosis. J Autoimmun 24:209-219

25. Bruggraber SF, Leung PS, Amano K, Quan C, Kurth MJ, Nantz MH, Benson GD, Van de Water J, Luketic V, Roche TE, Ansari AA, Coppel RL, Gershwin ME (2003) Autoreactivity to lipoate and a conjugated form of lipoate in primary biliary cirrhosis. Gastroenterology 125:1705-1713

26. Amano K, Leung PS, Rieger R, Quan C, Wang X, Marik J, Suen YF, Kurth MJ, Nantz MH, Ansari AA, Lam KS, Zeniya M, Matsuura E, Coppel RL, Gershwin ME (2005) Chemical xenobiotics and mitochondrial autoantigens in primary biliary cirrhosis: identification of antibodies against a common environmental, cosmetic, and food additive, 2-octynoic acid. J Immunol 174:5874-5883

27. Amano K, Leung PS, Xu Q, Marik J, Quan C, Kurth MJ, Nantz MH, Ansari AA, Lam KS, Zeniya M, Coppel RL, Gershwin ME (2004) Xenobiotic-induced loss of tolerance in rabbits to the mitochondrial autoantigen of primary biliary cirrhosis is reversible. J Immunol 172:6444-6452

28. Leung PS, Park O, Tsuneyama K, Kurth MJ, Lam KS, Ansari AA, Coppel RL, Gershwin ME (2007) Induction of primary biliary cirrhosis in guinea pigs following chemical xenobiotic immunization. J Immunol 179:2651-2657

29. Leung PS, Quan C, Park O, Van de Water J, Kurth MJ, Nantz MH, Ansari AA, Coppel RL, Lam KS, Gershwin ME (2003) Immunization with a xenobiotic 6-bromohexanoate bovine serum albumin conjugate induces antimitochondrial antibodies. J Immunol 170:5326-5332

30. Invernizzi P (2010) Geoepidemiology of autoimmune liver diseases. J Autoimmun 34:J300-J306

31. Czaja AJ, Carpenter HA, Santrach PJ, Moore SB (2000) Autoimmune cholangitis within the spectrum of autoimmune liver disease. Hepatology 31:1231-1238 
32. Miyakawa H, Tanaka A, Kikuchi K, Matsushita M, Kitazawa E, Kawaguchi N, Fujikawa H, Gershwin ME (2001) Detection of antimitochondrial autoantibodies in immunofluorescent AMAnegative patients with primary biliary cirrhosis using recombinant autoantigens. Hepatology 34:243-248

33. Lindor KD, Gershwin ME, Poupon R, Kaplan M, Bergasa NV, Heathcote EJ (2009) Primary biliary cirrhosis. Hepatology 50:291-308

34. Selmi C, Zuin M, Bowlus CL, Gershwin ME (2008) Antimitochondrial antibody-negative primary biliary cirrhosis. Clin Liver Dis 12:173-185, ix

35. Oertelt S, Rieger R, Selmi C, Invernizzi P, Ansari AA, Coppel RL, Podda M, Leung PS, Gershwin ME (2007) A sensitive bead assay for antimitochondrial antibodies: chipping away at AMA-negative primary biliary cirrhosis. Hepatology 45:659-665

36. Nakamura M, Kondo H, Mori T, Komori A, Matsuyama M, Ito M, Takii Y, Koyabu M, Yokoyama T, Migita K, Daikoku M, Abiru S, Yatsuhashi H, Takezaki E, Masaki N, Sugi K, Honda K, Adachi H, Nishi H, Watanabe Y, Nakamura Y, Shimada M, Komatsu T, Saito A, Saoshiro T, Harada H, Sodeyama T, Hayashi S, Masumoto A, Sando T, Yamamoto T, Sakai H, Kobayashi M, Muro T, Koga M, Shums Z, Norman GL, Ishibashi H (2007) Antigp210 and anti-centromere antibodies are different risk factors for the progression of primary biliary cirrhosis. Hepatology 45:118127

37. Goulis J, Leandro G, Burroughs AK (1999) Randomised controlled trials of ursodeoxycholic acid therapy for primary biliary cirrhosis: a meta-analysis. Lancet 354:1053-1060

38. Corpechot C, Carrat F, Bahr A, Chretien Y, Poupon RE, Poupon R (2005) The effect of ursodeoxycholic acid therapy on the natural course of primary biliary cirrhosis. Gastroenterology 128:297-303

39. Pares A, Caballeria L, Rodes J (2006) Excellent long-term survival in patients with primary biliary cirrhosis and biochemical response to ursodeoxycholic acid. Gastroenterology 130:715-720

40. Gershwin ME, Mackay IR (2008) The causes of primary biliary cirrhosis: convenient and inconvenient truths. Hepatology 47:737-745

41. Leung PS, Rossaro L, Davis PA, Park O, Tanaka A, Kikuchi K, Miyakawa H, Norman GL, Lee W, Gershwin ME (2007) Antimitochondrial antibodies in acute liver failure: implications for primary biliary cirrhosis. Hepatology 46:1436-1442

42. Nishio A, Van de Water J, Leung PS, Joplin R, Neuberger JM, Lake J, Bjorkland A, Totterman TH, Peters M, Worman HJ, Ansari AA, Coppel RL, Gershwin ME (1997) Comparative studies of antimitochondrial autoantibodies in sera and bile in primary biliary cirrhosis. Hepatology 25:1085-1089

43. Tanaka A, Nalbandian G, Leung PS, Benson GD, Munoz S, Findor JA, Branch AD, Coppel RL, Ansari AA, Gershwin ME (2000) Mucosal immunity and primary biliary cirrhosis: presence of antimitochondrial antibodies in urine. Hepatology 32:910-915

44. Reynoso-Paz S, Leung PS, Van De Water J, Tanaka A, Munoz S, Bass N, Lindor K, Donald PJ, Coppel RL, Ansari AA, Gershwin ME (2000) Evidence for a locally driven mucosal response and the presence of mitochondrial antigens in saliva in primary biliary cirrhosis. Hepatology 31:24-29

45. Ikuno N, Mackay IR, Jois J, Omagari K, Rowley MJ (2001) Antimitochondrial autoantibodies in saliva and sera from patients with primary biliary cirrhosis. J Gastroenterol Hepatol 16:13901394

46. Tanaka A, Nezu S, Uegaki S, Mikami M, Okuyama S, Kawamura N, Aiso M, Gershwin ME, Takahashi S, Selmi C, Takikawa H (2007) The clinical significance of $\operatorname{IgA}$ antimitochondrial antibodies in sera and saliva in primary biliary cirrhosis. Ann NY Acad Sci 1107:259-270

47. van der Windt DA, Jellema P, Mulder CJ, Kneepkens CM, van der Horst HE (2010) Diagnostic testing for celiac disease among patients with abdominal symptoms: a systematic review. JAMA 303:1738-1746

48. Chazouilleres O, Wendum D, Serfaty L, Montembault S, Rosmorduc O, Poupon R (1998) Primary biliary cirrhosisautoimmune hepatitis overlap syndrome: clinical features and response to therapy. Hepatology 28:296-301

49. Deshmukh US, Bagavant H, Fu SM (2006) Role of anti-DNA antibodies in the pathogenesis of lupus nephritis. Autoimmun Rev 5:414-418

50. Moritoki Y, Lian ZX, Lindor K, Tuscano J, Tsuneyama K, Zhang W, Ueno Y, Dunn R, Kehry M, Coppel RL, Mackay IR, Gershwin ME (2009) B-cell depletion with anti-CD20 ameliorates autoimmune cholangitis but exacerbates colitis in transforming growth factor-beta receptor II dominant negative mice. Hepatology 50:1893-1903

51. Mattalia A, Luttig B, Rosina F, Leung PS, Van de Water J, Bauducci M, Ciancio A, Boker KH, Worman H, Cooper RL, Manns M, Ansari A, Rizzetto M, Gershwin ME (1997) Persistence of autoantibodies against recombinant mitochondrial and nuclear pore proteins after orthotopic liver transplantation for primary biliary cirrhosis. J Autoimmun 10:491497

52. Lleo A, Selmi C, Invernizzi P, Podda M, Coppel RL, Mackay IR, Gores GJ, Ansari AA, Van de Water J, Gershwin ME (2009) Apotopes and the biliary specificity of primary biliary cirrhosis. Hepatology 49:871-879

53. Lleo A, Bowlus CL, Yang GX, Invernizzi P, Podda M, Van de Water J, Ansari AA, Coppel RL, Worman HJ, Gores GJ, Gershwin ME (2010) Biliary apotopes and anti-mitochondrial antibodies activate innate immune responses in primary biliary cirrhosis. Hepatology 52:987-998

54. Odin JA, Huebert RC, Casciola-Rosen L, LaRusso NF, Rosen A (2001) Bcl-2-dependent oxidation of pyruvate dehydrogenase-E2, a primary biliary cirrhosis autoantigen, during apoptosis. J Clin Invest 108:223-232

55. Invernizzi P, Selmi C, Ranftler C, Podda M, Wesierska-Gadek J (2005) Antinuclear antibodies in primary biliary cirrhosis. Semin Liver Dis 25:298-310

56. Granito A, Muratori P, Muratori L, Pappas G, Cassani F, Worthington J, Guidi M, Ferri S, DEM C, Lenzi M, Chapman RW, Bianchi FB (2006) Antinuclear antibodies giving the 'multiple nuclear dots' or the 'rim-like/membranous' patterns: diagnostic accuracy for primary biliary cirrhosis. Aliment Pharmacol Ther 24:1575-1583

57. Bogdanos DP, Liaskos C, Pares A, Norman G, Rigopoulou EI, Caballeria L, Dalekos GN, Rodes J, Vergani D (2007) Anti-gp210 antibody mirrors disease severity in primary biliary cirrhosis. Hepatology 45:1583, author reply 1583-1584

58. Invernizzi P, Podda M, Battezzati PM, Crosignani A, Zuin M, Hitchman E, Maggioni M, Meroni PL, Penner E, WesierskaGadek J (2001) Autoantibodies against nuclear pore complexes are associated with more active and severe liver disease in primary biliary cirrhosis. J Hepatol 34:366-372

59. Mattalia A, Quaranta S, Leung PS, Bauducci M, Van de Water J, Calvo PL, Danielle F, Rizzetto M, Ansari A, Coppel RL, Rosina F, Gershwin ME (1998) Characterization of antimitochondrial antibodies in health adults. Hepatology 27:656-661

60. Fulton RJ, McDade RL, Smith PL, Kienker LJ, Kettman JR Jr (1997) Advanced multiplexed analysis with the FlowMetrix system. Clin Chem 43:1749-1756

61. de Jager W, te Velthuis H, Prakken BJ, Kuis W, Rijkers GT (2003) Simultaneous detection of 15 human cytokines in a single sample of stimulated peripheral blood mononuclear cells. Clin Diagn Lab Immunol 10:133-139

62. Jia XC, Raya R, Zhang L, Foord O, Walker WL, Gallo ML, Haak-Frendscho M, Green LL, Davis CG (2004) A novel 
method of multiplexed competitive antibody binning for the characterization of monoclonal antibodies. J Immunol Methods 288:91-98

63. Surh CD, Coppel R, Gershwin ME (1990) Structural requirement for autoreactivity on human pyruvate dehydrogenase-E2, the major autoantigen of primary biliary cirrhosis. Implication for a conformational autoepitope. J Immunol 144:3367-3374

64. Padgett KA, Lan RY, Leung PC, Lleo A, Dawson K, Pfeiff J, Mao TK, Coppel RL, Ansari AA, Gershwin ME (2009) Primary biliary cirrhosis is associated with altered hepatic microRNA expression. J Autoimmun 32:246-253

65. Hirschfield GM, Liu X, Xu C, Lu Y, Xie G, Gu X, Walker EJ, Jing K, Juran BD, Mason AL, Myers RP, Peltekian KM, Ghent CN, Coltescu C, Atkinson EJ, Heathcote EJ, Lazaridis KN, Amos CI, Siminovitch KA (2009) Primary biliary cirrhosis associated with HLA, IL12A, and IL12RB2 variants. N Engl J Med 360:2544-2555

66. Liu X, Invernizzi P, Lu Y, Kosoy R, Lu Y, Bianchi I, Podda M, Xu C, Xie G, Macciardi F, Selmi C, Lupoli S, Shigeta R, Ransom M, Lleo A, Lee AT, Mason AL, Myers RP, Peltekian KM, Ghent CN, Bernuzzi F, Zuin M, ICPBCG ICfPBCG, Gregersen PK, Heathcote EJ, Hirschfield GM, Siminovitch KA, Amos CI, Gershwin ME, Seldin MF (2010) Genome-wide meta-analyses identifies three loci associated with primary biliary cirrhosis. Nat Genet (in press)

67. Brooks WH, Le Dantec C, Pers JO, Youinou P, Renaudineau Y (2010) Epigenetics and autoimmunity. J Autoimmun 34:J207J219

68. Hewagama A, Richardson B (2009) The genetics and epigenetics of autoimmune diseases. J Autoimmun 33:3-11 